\title{
PENGARUH KEMUDAHAN PENGGUNAAN, KUALITAS INFORMASI, KUALITAS INTERAKSI, TERHADAP KEPUASAN PENGGUNA APLIKASI OPEN SOURCE MENGGUNAKAN WEBQUAL
}

\author{
Wahyu Widodo ${ }^{1}$, Ayuna Septita Dahlia ${ }^{2}$ Deddy Ardiansyah $^{3}$ \\ ${ }^{1,2}$ Prodi Teknik Informatika, STMIK El Rahma Yogyakarta \\ ${ }^{3}$ Prodi Sistem Informasi, STMIK El Rahma Yogyakarta \\ E-mail: ${ }^{1}$ wahyu@stmikelrahma.ac.id ${ }^{2}$ ayunadahlia@gmail.com, ${ }^{3}$ ardiansyahdeddy@gmail.com
}

(Naskah masuk: 6 Maret 2020, diterima untuk diterbitkan: 23 Maret 2020)

\begin{abstract}
Abstrak
OpenSID merupakan Sistem Informasi Desa (SID) yang digunakan untuk mengembangkan sistem informasi di desa, dirancang supaya dapat dikembangkan secara kolaborasi oleh para komunitas peduli SID. Kualitas aplikasi merupakan hal yang penting dalam suatu pengembangan sistem informasi. Sebuah sistem harus dapat memenuhi kepentingan dan keinginan pemakai. Saat ini Open SID digunakan untuk menunjang proses input dan output data-data desa. Selama penggunaan ini belum diketahui sikap pengguna terhadap kegunaan atau kualitas dari aplikasi tersebut dan banyak pengembang baru yang bergabung untuk berkontribusi dengan kemampuan yang berbeda-beda sehingga berpengaruh terhadap kualitas aplikasi, maka perlu adanya evaluasi. Hasil evaluasi sangat bermanfaat untuk dijadikan acuan dalam melakukan perencanaan perbaikan proses kualitas aplikasi. Metode pengukuran kualitas aplikasi menggunakan WebQual yang merupakan salah satu teknik pengukuran kualitas aplikasi berbasis website berdasarkan persepsi pengguna akhir. Hasil penelitian terdapat temuan bahwa kepuasan penggunaan aplikasi OpenSID ada pada kualitas informasi yaitu informasi mudah di dapat, tepat waktu, dan relevan.
\end{abstract}

Kata kunci: WebQual, Kualitas Interaksi, Kemudahan Pengguna, Kualitas Informasi, Opensource

\section{EFFECT OF EASY TO USE QUALITY, INFORMATION OF QUALITY, INTERACTION OF QUALITY,AND THE USER SATISFACTION FOR OPEN SOURCE APPLICATIONS USING THE WEBQUAL METHOD}

\begin{abstract}
OpenSID is a Village Information System (SID) that is used to develop information systems in villages, designed to be developed collaboratively by SID caring communities. The quality of the application is important in the development of information systems. A system must be able to meet the interests and desires of users. Currently Open SID is used to support the process of input and output of village data. As long as this usage is not known the user's attitude towards the usefulness or quality of the application and many new developers who join to contribute with different abilities so that it affects the quality of the application, it is necessary to evaluate. Evaluations like these are used to plan for changes that are implemented in the future. The method of measuring the quality of applications using WebQual which is one of the techniques of measuring the quality of websitebased applications based on the perception of end users. The results of the study found that the satisfaction of using the OpenSID application is on the quality of information that is information that is easy to obtain, timely, and relevant.
\end{abstract}

Keywords: WebQual, Quality of Interaction, Quality of Information, Opensource

\section{PENDAHULUAN}

Aplikasi open source secara umum merupakan kode terbuka, biasanya didistribusikan untuk publik dan mengizinkan orang lain mengetahui cara kerja supaya bisa menggunakan, membaca kode sumber aplikasi, melakukan modifikasi, dan juga berhak mendistribusikan kembali dengan lisensi yang sama, dengan syarat-syarat tertentu, misalnya dengan tetap membuka source code, dan menyertakan kode aslinya [1]. Aplikasi OpenSID merupakan Sistem Informasi Desa (SID) yang berbasis open source yang digunakan untuk mengembangkan sistem informasi di desa, yang dirancang supaya komunitas peduli SID dapat saling berkolaborasi dalam mengembangkan aplikasi[2]. 
Kualitas sebuah aplikasi merupakan hal penting dalam suatu pengembangan sistem informasi. Sebuah sistem harus dapat memenuhi kepentingan dan keinginan pemakai [3]. Saat ini Open SID digunakan untuk menunjang proses input dan output data-data desa. Selama penggunaan ini belum diketahui sikap pengguna terhadap kegunaan atau kualitas dari aplikasi tersebut dan banyak pengembang baru yang bergabung untuk berkontribusi dengan kemampuan yang berbedabeda sehingga berpengaruh terhadap kualitas aplikasi, maka perlu adanya evaluasi [4]. Evaluasi seperti ini dimanfaatkan untuk membuat perencanaan dalam perbaikan yang diimplementasikan di masa yang akan datang. Proses pengembangan aplikasi juga dapat merujuk dari hasil identifikasi yang diperoleh dari hasil evaluasi [5].

Tujuan dari penelitian ini untuk mengukur pengaruh kualitas kemudahan penggunaan (Usability) terhadap kepuasan pengguna, mengukur pengaruh kualitas informasi (information quality) terhadap kepuasan pengguna, mengukur pengaruh kualitas interaksi (interaction quality) terhadap kepuasan pengguna. Metode pengukuran kualitas aplikasi menggunakan WebQual yang merupakan salah satu metode atau teknik pengukuran kualitas aplikasi berbasis website berdasarkan persepsi pengguna akhir [6].

\section{METODE PENELITIAN}

[7] melakukan penelitian tentang evaluasi kualitas website Politeknik Negeri Sriwijaya dengan metode WebQual. Penelitian ini menggunakan metode penelitian deskriptif kuantitatif dengan melakukan survei dan pengumpulan data primer melalui wawancara dengan penyebaran kuesioner kepada pengguna website polsri sebagai responden. Kemudian dilakukan studi literatur untuk mengumpulkan teori-teori yang berkaitan dengan permasalahan tersebut sehingga dapat ditentukan model serta variabel penelitiannya. Kesimpulannya bahwa secara keseluruhan kualitas kegunaan, kualitas informasi, dan kualitas desain berpengaruh positif terhadap kepuasaan pengguna. Dan yang paling domiman berpengaruh positif terhadap kepuasan pengguna adalah kualitas kegunaan.

[8] meneliti tentang analisis pengaruh kualitas website terhadap kepuasan pengguna pada Universitas Narotama.Untuk mengukur kualitas website Universitas tersebut, dilakukan dengan menganalisis pengaruh kualitas informasi, interaksi, dan penggunaan website terhadap kepuasan pengguna. Hasil yang didapatkan yaitu kualitas penggunaan tidak berpengaruh positif dan signifikan terhadap kepuasan pengguna mahasiswa dan civitas Universitas Narotama. Sedangkan [12] membangun website untuk promosi ekowisata.

Metode kuantitatif merupakan metode yang bisa digunakan untuk survey guna mendapatkan data yang telah terjadi pada masa lampau atau masa kini tentang pendapat, perilaku, keyakinan untuk menguji beberapa hipotesis. Tahapan penelitian diawali dengan perumusan masalah, mempelajari metode WebQual dan mengumpulkan data yang berhubungan dengan permasalahan yang dibahas sehingga dapat membantu menyelesaikan permasalahan terhadap pengukuran website dan variabel penelitian untuk mendukung dalam penyusunan kuesioner. Setelah kuesioner jadi maka dilakukan penyebaran kuesioner untuk mendapatkan data dari responden yang dilanjutkan dengan rekap data dan pengolahan data dengan menggunakan software Smart PLS (Partial Least Square) untuk menguji validitas, mengujiuji reliabilitas, serta melakukan analisis statistik kemudian dilakukan pengujian measurement model.Tahapan terakhir yaitu menyimpulkan dan merekomendasikan hasil penelitian. Tahapan penelitian ini seperti terlihat pada Gambar 1.

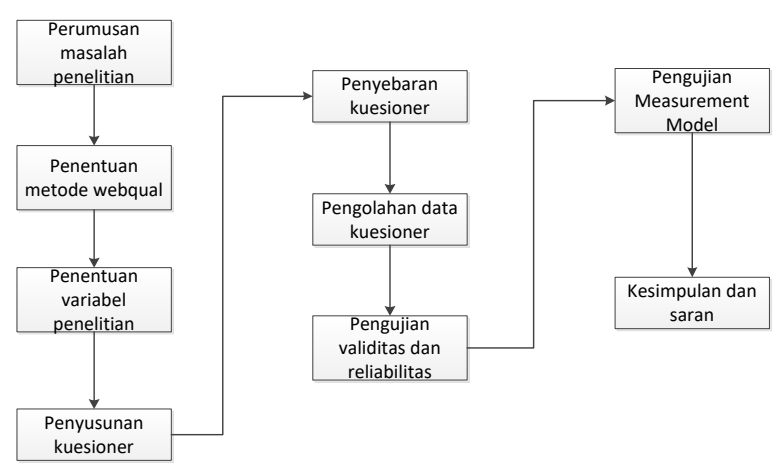

Gambar 1. Tahapan Penelitian

\subsection{Penentuan Metode WebQual}

Hipotesa pada penelitian menggunakan metode webqual ini terdiri dari 3 dimensi yaitu kegunaan , kualitas informasi dan kualitas yang mana layanan mempengaruhi kepuasan pengguna.Kualitas ini termuat dalam tiga dimensi dari WebQual versi 4.0, Dimensi WebQual dapat memprediksi kepuasan pengguna dan maksud pengguna dalam menggunakan kembali website [9]. Hipotesa pada analisa kualitas Open SID dapat dilihat pada Gambar 2.

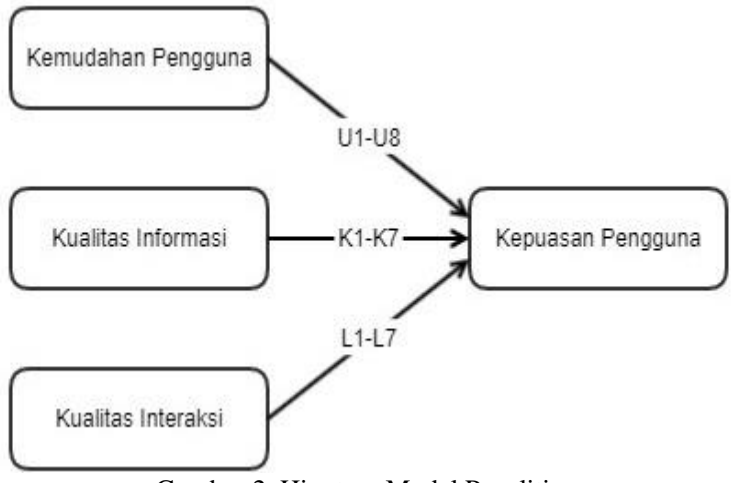

Gambar 2. Hipotesa Model Penelitian 


\subsection{Penentuan Variabel Penelitian}

Variable ini digunakan untuk mengukur kualitas website berdasarkan persepsi pengguna akhir dengan tiga kategori pengukuran dengan 22 butir pertanyaan. Kategori usability berdasar dari kajian mengenai hubungan antara manusia dan komputer dan kajian mengenai kegunaan web, diantaranya mengenai kemudahan navigasi, kecocokan desain dan gambaran yang disampaikan kepada pengguna[10]. Kategori information dikaji berdasarkan kajian sistem informasi secara umum. Kategori ini berhubungan terhadap kualitas dari konten website yaitu kepantasan informasi bagi tujuan pengguna, misalnya mengenai akurasi, format dan relevansi dari informasi yang disajikan. Kategori service interaction berhubungan terhadap interaksi layanan yang dirasakan pengguna ketika terlibat secara mendalam dengan website.

Variabel pertama (memiliki 8 indikator, yaitu U1-U8) adalah kegunaan, kedua (memiliki 7 indikator, yaitu K1-K7) adalah kualitas informasi, dan ketiga (memiliki 7 indikator, yaitu L1-L7) adalah kualitas interaksi. Desain penelitian yaitu digunakan untuk melihat pengaruh antara variabel bebas terhadap variabel terikat.Sedangkan variabel terikatnya (Y) adalah kepuasan pengguna.

Variable penelitian antara lain.

U memiliki 8 indikator (U1-U8) : Kualitas kegunaan U1-U8 mempunyai pengaruh signifikan terhadap Y kepuasan pengguna.

$\mathrm{K}$ memiliki 7 indikator (K1-K7): Kualitas informasi $\mathrm{K} 1-\mathrm{K} 7$ mempunyai pengaruh signifikan terhadap Y kepuasan pengguna.

L memiliki 7 indikator (L1-L7): Kualitas interaksi layanan L1-L7 mempunyai pengaruh signifikan terhadap Y kepuasan pengguna.Variabel pertama memiliki 8 indikator, yaitu U1-U8 adalah kegunaan seperti pada Tabel 1.

Table 1 Pertanyaan Variabel Kemudahan Pengguna

\begin{tabular}{|c|c|}
\hline Pertanyaan & Kode \\
\hline $\begin{array}{l}\text { Aplikasi OpenSID merupakan aplikasi yang mudah } \\
\text { untuk dioperasikan }\end{array}$ & U1 \\
\hline $\begin{array}{l}\text { Menu-menu dalam aplikasi Open SID dapat mudah } \\
\text { dimengerti }\end{array}$ & U2 \\
\hline $\begin{array}{l}\text { Desain warna aplikasi Open SIDmenarik untuk } \\
\text { dilihat }\end{array}$ & U3 \\
\hline $\begin{array}{l}\text { Jenis dan ukuran huruf di aplikasi Open SID mudah } \\
\text { dibaca }\end{array}$ & U4 \\
\hline $\begin{array}{l}\text { Antar halaman pada aplikasi Open SID cepat } \\
\text { ditampilkan }\end{array}$ & U5 \\
\hline $\begin{array}{l}\text { Aplikasi open SID bisa diakses online sesuai } \\
\text { dengan domain nama desa }\end{array}$ & U6 \\
\hline $\begin{array}{l}\text { Aplikasi open SID mengandung kompentensi } \\
\text { pembelajaran }\end{array}$ & U7 \\
\hline $\begin{array}{l}\text { Aplikasi Open SID menciptakan pengalaman } \\
\text { positif bagi pengguna }\end{array}$ & U8 \\
\hline
\end{tabular}

Table 2 Pertanyaan Variabel Kualitas Informasi

\begin{tabular}{ll}
\hline \multicolumn{1}{c}{ Pertanyaan } & Kode \\
\hline $\begin{array}{l}\text { Aplikasi Open SID dapat menyajikan informasi } \\
\text { desa yang akurat dan jelas }\end{array}$ & K1 \\
$\begin{array}{l}\text { Aplikasi Open SID dapat memberikan informasi } \\
\text { desa yang dapat dipercaya }\end{array}$ & K2 \\
$\begin{array}{l}\text { Aplikasi Open SID dapat memberikan informasi } \\
\text { desa terkini (up to date). }\end{array}$ & K3 \\
$\begin{array}{l}\text { Aplikasi Open SID dapat memberikan Informasi } \\
\text { bermanfaat untuk pengguna }\end{array}$ & K4 \\
$\begin{array}{l}\text { Aplikasi Open SID dapat menyediakan informasi } \\
\text { yang mudah dimengerti }\end{array}$ & K5 \\
$\begin{array}{l}\text { Aplikasi Open SID dapat menyediakan informasi } \\
\text { desa yang rinci dan detail }\end{array}$ & K6 \\
$\begin{array}{l}\text { Dengan Aplikasi Open SID dapat menambah } \\
\text { pengetahuan dan informasi desa. }\end{array}$ & K7 \\
\hline
\end{tabular}

Variable ketiga memiliki 7 indikator, yaitu L1L7 adalah kualitas interaksi seperti pada Tabel 3.

Table 3 Pertayaan Variabel Kualitas Informasi Pertanyaan Kode

Aplikasi mempunyai rekam jejak yang bagus L1

Pemerintah desa percaya dan yakin dengan datadata yang diupdate pada aplikasi Open SID L2

Pengguna merasa aman terhadap informasi desa dan data-data masyarakat

Aplikasi memberikan data-data nyata desa sehingga masyarakat dapat mengakses mendapat informasi

Aplikasi memberikan ruang untuk komunitas

Aplikasi memberikan kemudahan untuk berkomunikasi dengan Organisasi

Pegiat atau pengembang aplikasi Open SID merespon pertanyaan dan memberikan tanggapan L7 sangat cepat

\subsection{Penyebaran Kuisioner}

Responden objek dalam penelitian ini dibatasi hanya pada pengguna dan pegiat Open SID yang telah mengunakan sistem informasi ini.Dalam hal ini sampel yang di ambil adalah pengguna dan pegiat OpenSID. Kuesioner yang dilakukan yaitu menggunakan skala likert yang berfungsi untuk mengukur persepsi, sikap atau pendapat seseorang atau kelompok mengenai sebuah peristiwa atau fenomena sosial, berdasarkan definisi operasional yang telah ditetapkan oleh peneliti.Penarikan sampel yang digunakan adalah kuesioner tertutup dengan jawaban yang tersedia berupa angka-angka interval dari 1 sampai 5. Kuesioner yang digunakan memuat pertanyaan-pertanyaan berbentuk skala bertingkat dituliskan dalam format skala likert yaitu Sangat setuju, Setuju, Netral, Ragu-ragu,Tidak setuju seperti pada Tabel 4 . 


\begin{tabular}{lll}
\multicolumn{3}{c}{ Table 4 Skala Likerd } \\
\hline Jawaban & Skala & Nilai \\
\hline Sangat Setuju & SS & 5 \\
Setuju & S & 4 \\
Netral & N & 3 \\
Ragu-Ragu & RR & 2 \\
Tidak Setuju & TS & 1 \\
\hline
\end{tabular}

Penyebaran kuesioner dilakukan di sebuah forum facebook pengguna dan pegiat open SID. Kuesioner tertutup dengan jawaban yang tersedia berupa angka-angka interval dari 1 sampai 5 .

\section{HASIL DAN PEMBAHASAN}

\subsection{Perhitungan Validitas}

Pada Uji validitas ini digunakan untuk mengetahui kelayakan butir-butir pertanyaan atau kuesioner yang diisi oleh 51 orang responden tersebut layak atau belum untuk diambil datanya.Uji validitas ini dilakukan pada setiap butir pertanyaan yaitu 22 pertanyaan.Hasil uji validitas dengan menggunakan jumlah responden 51. Nilai outerloading berdasarkan hasil validitas konstruk kualitas kemudahan penggunaan (U), kualitas informasi (K), kualitas interaksi (L), nilai diatas angka 0,5 , jadi dapat disimpulkan bahwa semua indikator dapat memenuhi validitas konvergen (convergent validity). Pada Gambar 3 merupakan hasil dari pengujian validitas.

Bootstrapping (Run No. 4) $\mathbb{3}$

\section{Outer Loadings}

Mean, STDEV, T-Val... 贯 Confidence Interva... 圂 Confidel Original Sample (0)

\begin{tabular}{ll} 
U7 <- U (kegunaan/ Usability) & 0.717 \\
\hline U7 <- User Satisfaction & 0.720 \\
\hline U8 <- U (kegunaan/ Usability) & 0.581 \\
\hline U8 <- User Satisfaction & 0.518
\end{tabular}

Gambar 3 Hasil Pengujian Validitas

Nilai average varians extracted (AVE) juga dapat memvisualisasikan dari pengujian validitas konvergensi. Pada tabel diatas hasil perhitungan nilai AVE bahwa semua variabel penelitian sesuai dengan standar yaitu semua konstruk memiliki angka lebih dari 0,5 , sehingga penelitian ini memenuhi syarat dapat dikatakan valid.

Langkah selanjutnya melakukan uji validasi deskriminan dengan cara melakukan perbandingan antara akar AVE yang digunakan sebagai konstruk dengan korelasi nilai antar konstruk lain, seperti pada Tabel 5. Validasi diskriminan ini memenuhi kriteria karena setiap konstruk memiliki akar AVE yang lebih besar jika dibandingkan dengan nilai konstruk yang lain.

\begin{tabular}{ccc}
\multicolumn{3}{c}{ Table 5 Akar AVE } \\
\hline Variabel & AVE & Akar AVE \\
\hline K (Information Quality) & 0,669 & 0,817924202 \\
L (Interaction Quality) & 0,595 & 0,771362431 \\
U (Usability) & 0,534 & 0,730753036 \\
\hline
\end{tabular}

\subsection{Perhitungan Reliabilitas}

Semakin nilainya mendekati 1 , semakin besar konsistensi internal item-item di dalam kuesioner [11].

Hasil uji reliabilitas diperoleh nilai koefisien realibilitas angket kegunaan (U) sebesar 0,888, angket kualitas informasi (K) sebesar 0,934, angket interaksi layanan (L) sebesar 0,895 dan angket kepuasan pengguna/ user satisfaxtion (Y) sebesar 0,9468 hasil pengujian ditunjukkan pada Gambar 4. Berdasarkan nilai koefisien reliabilitas tersebut dapat disimpulkan bahwa semua angket dalam peneltian ini reliabel atau konsisten, sehingga dapat digunakan sebagai instrumen.

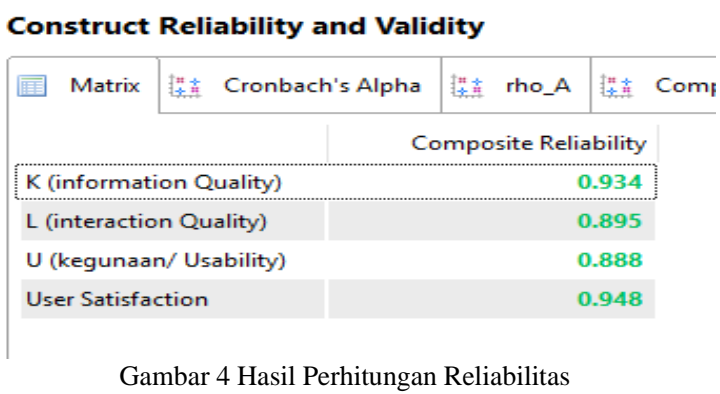

Hasil perhitungan pada Gambar 4 telah memenuhi syarat compositereliability, karena nilai pada seluruh variabel telah memiliki angka $>0,70$. Sedangkan pada Tabel 6, merupakan hasil pengujian Cronbach alpha dengan nilai masing-masing variabel lebih dari 0,70 sehingga dapat diambil keseimpulan bahwa penelitian ini memenuhi uji reliabilitas.

\begin{tabular}{cc}
\multicolumn{2}{c}{ Tabel 6 Nilai Cronbach's alpha } \\
\hline Variabel & Cronbach'salpha \\
\hline $\mathrm{K}$ & 0,917 \\
\hline $\mathrm{L}$ & 0,857 \\
\hline $\mathrm{U}$ & 0,831 \\
\hline User Satisfaction & 0,939 \\
\hline
\end{tabular}

\subsection{Perhitungan Inner Model}

Pada proses uji Inner model dapat dilihat bahwa angka nilai T-statistic 0,436 yang berarti signifikan terdapat pengaruh positif terhadap kemudahan kegunaan, kualitas informasi, kualitas interaksi terhadap kepuasan. Semakin baik kemudahan kegunaan, kualitas informasi, kualitas interaksi sistem Informasi Desa maka semakin meningkat kepuasan pemakai (pemerintah desa).

Pada proses uji hipotesis 1 digunakan untuk mengidentifikasi apakah ada hubungan positif koefisien kemudahan antara kemudahan kegunaan, 
kualitas informasi, kualitas interaksi terhadap kepuasan pengguna. Dari hasil pengolahan data didapatkan bahwa nilai kemudahan kegunaan terhadap kepuasan pengguna sebesar 0,350 drngan nilai statistik 13.300. pada tingkat signifikansi 0,05 (t-statistik lebih besar dari t-tabel 1,64) maka hipotesis 1 yang menyatakan kemudahan penggunaan terhadap kepuasan pengguna adalah positif dan signifikanse sehingga hipotesa 1 terdukung.

Selanjutnya pada proses pengujian hipotesis kedua dimaksudkan untuk mengetahui apakah terdapat hubungan positif koefisien kemudahan antara kemudahan kegunaan, kualitas informasi, kualitas interaksi dengan kepuasan pengguna. Nilai kualitas informasi terhadap kepuasan pengguna adalah 0,436 dengan nilai t statistik 12.411 ada pada angka tingkat signifikansi 0,05 (t-statistik>t-tabel 1,64) maka dari itu hipotesis 2 yang menyatakan kualitas Informasi terhadap kepuasan pengguna adalah positif dan signifikanse sehingga hipotesa 2 terpenuhi.

Langkah terakhir pada proses hipotesis 3 digunakan untuk melacak hubungan positif koefisien kemudahan dengan kemudahan kegunaan, kualitas informasi, kualitas interaksi terhadap kepuasan pengguna. Hasil yang diperoleh nilai kualitas informasi terhadap kepuasan pengguna adalah 0,327 dengan nilai t statistik 10,962 masih masuk ditingkat signifikansi 0,05 jadi pada proses pembuktian hipotesis 3, kualitas interaksi terhadap kepuasan pengguna adalah positif dan signifikanse sehingga hipotesa 3 terpenuhi.

\subsection{Penjelasan Hipotesa}

Dari hasil pengukuran variabel kemudahan pengguna, nilai indikator U1 $(0,334), \mathrm{U} 6(0,668)$, dan U8 $(0,574)$ memiliki kontribusi terkecil karena nilai outerloding kurang dari 0,7. Dengan demikian Aplikasi Open SID masih dirasa tidak mudah untuk dioperasikan. Aplikasi Open SID dapat di akses online dengan domain desa, tetapi pemerintah desa belum memahami cara kerjanya sehingga masih perlu perbaikan dari sisi interface agar mudah dioperasikan oleh pengguna. Adapun variabel yang memiliki kontribusi nilai besar adalah U3 $(0,809)$, artinya aplikasi OpenSID memiliki tampilan warna desain yang menarik.

Variabel kualitas informasi semua indikator memiliki angka outer loading diatas 0,7 , jadi semua variabel kualitas informasi memberikan korelasi yang positif. Indikator K4 $(0,875)$ memiliki nilai paling besar, maka dapat disimpulkan bahwa aplikasi OpenSID dapat memberikan nilai yang bermanfaat bagi pengguna.

Pengukuran variabel kualitas interaksi, indikator L5 (0,541), L6 (0,578), dan L7 $(0,621)$ masih memberikan kontribusi kecil karena masih dibawah nilai outer loading (0,7). Jadi menurut persepsi pengguna Aplikasi, belum dapat memberikan ruang yang cukup untuk komunitas untuk berkomunikasi dengan organisasi, komunikasi dengan para OpenSID, kurang dalam memberi tanggapan yang cepat saat ada pengguna yang bertanya. Adapun kontribusi paling besar diberikan ada pada indikator L2 $(0,881)$ yang artinya pemerintah desa merasa nyaman untuk melakukan perubahan data-data penduduk pada aplikasi.

\section{KESIMPULAN}

Berdasarkan dari hasil diatas dapat disimpulkan bahwa indikator L5 $(0,541)$, L6 $(0,578)$, dan L7 (0,621) masih memberikan kontribusi kecil karena menurut persepsi pengguna Aplikasi Open SID belum memberikan ruang yang cukup untuk komunitas, Aplikasi Open SID belum memberikan kemudahan untuk berkomunikasi dengan organisasi, serta pegiat atau pengembang aplikasi ini tidak memberi tanggapan dan respon yang cepat saat ada pengguna yang bertanya. Sedangkan indikator L2 $(0,881)$ memiliki kontribusi besar yang artinya pemerintah desa merasa aman untuk melakukan perubahan data pada aplikasi. Dari analisa pengukuran kualias Aplikasi OpenSID pendapat kepuasan pengguna adalah :

- Aplikasi ini tidak mudah atau masih dirasa sulit untuk di operasikan.

- Aplikasi dapat di akses online dengan domain desa, tetapi pemerintah desa belum memahami cara kerjanya.

- Aplikasi dirasa masih belum bisa menciptakan pengalaman positif bagi pengguna.

- Aplikasi belum memberikan ruang yang cukup untuk komunitas.

- Aplikasi belum memberikan kemudahan untuk berkomunikasi dengan organisasi.

Pegiat atau pengembang aplikasi Open SID tidak memberi tanggapan dan respon yang cepat saat ada pengguna yang bertanya.Kepuasan pengguna positif ada di Kualitas Informasi yaitu informasi mudah di dapat, tepat waktu, up to date dan relevan. Agar Aplikasi Open SID dapat berkembang, saran untuk apliaksi ini adalah sebagai berikut.

Variable kemudahan kegunaan, perlu diperbaiki yaitu perlu meningkatkan desain tampilan yang mudah dioperasikan bagi pengguna. Sedangan variabel kualitas interaksi, perlu adanya dukungan layanan teknis yang baik dan bisa menjawab semua kendala yang dihadapi.

\section{DAFTAR PUSTAKA}

[1] S. Surahmat dan A. Tenggono. 2018. "Evaluasi Penggunaan Aplikasi Office Berbasis Open Source pada SMKN Kota Palembang dengan Pendekatan Technology Acceptance Model." Jurnal Sisfokom, vol. 7, no. 2, pp. 98-103, doi:10.32736/sisfokom.v7i2.569.

[2] M. Mukmin., 2019. "Sosialisasi "Sistem Informasi Desa Berbasis Open Source (Opensid 1811) Di Desa Lipukasi Kabupaten 
Barru." Sekolah Tinggi Ilmu Administrasi AlGazali Barru.

[3] M. W. Fitrayana., B. Hariadi dan E. Rahmawati., 2018. "Analisis Pengaruh Kualitas Layanan Website DRPD Provinsi Jawa Timur Terhadap Kepuasan Pengguna dengan Metode WebQual 4.0 Modifikasi”., Jurnal JSIKA. Vol. 7(1), 1-8.

[4] W. Widodo. 2016., "Evaluasi Proses Pengembangan Perangkat Lunak Pada Virtual Team Development Menggunakan Cmmi Versi 1.3." Jurnal Informatika Ahmad Dahlan, vol. 10, no. 1 .pp.1140-1148.

[5] Wijanarko, W. (2005). Impelementasi Metrik pada pengebangan perangkat lunak.Skripsi

[6] R. E. Riyanto and S. B. Otong. 2019. "Analisis Pengukuran Kualitas Website terhadap Kepuasan Pengguna Berdasarkan Webqual 4.0." Jurnal Ilmiah Intech, vol. 1, no. 01, pp. 89-97.

[7] A. Manik., I. Salamah dan E. Susanti. 2017. "Metode WebQual 4.0 untuk evaluasi kualitas website Politeknik Negeri Sriwijaya"., Prosiding SNATIF ke-4. pp. 355-361.ISBN 978-602-1180-50-1.

[8] E. A. Wawoluamaya., D. Sunarto dan S. H. E. Wulandari., 2016. "Analisis Pengaruh Kualitas Website Terhadap Kepuasan Pengguna Berdasarkan Metode Webqual 4.0 Pada Universitas Narotama"., JSIKA. vol.5(11), pp. $1-8$.

[9] A. Y. Rezkiani, dkk. 2018. "Pengukuran Kualitas Website Unit Pengembangan Karir dan Kewirausahaan Universitas Brawijaya Menggunakan Metode Webqual 4 “., Jurnal Pengembangan Teknologi Informasi dan Ilmu Komputer. Vol 2 (2). pp.523-532.

[10] N. Aini, et al. 2019. "Evaluasi Website Pemerintah Kota Prabumulih melalui Pendekatan Website Usability Evaluation (Webuse)." Jurnal Ilmiah Betrik, vol. 10, no. 01, pp. 1-6, doi:10.36050/betrik.v10i01.20.

[11] Sanjaya, I. 2012. Pengukuran Kualitas Layanan Website Kementerian Kominfo Dengan Menggunakan Metode Webual 4.0," Jurnal Penelitian IPTEK-KOM. Vol.14(1). pp.1-14.

[12] A. Khairan dan S. Lutfi I. 2020. "Pembuatan Website Portal Ekonomi Dan Wisata (Ekowisata) Di Pulau Maitara Kota Tidore Kepulauan," JIKO (Jurnal Informatika dan Komputer). Vol.3(1). pp.13-18. 